\title{
Standardization as Spaces of Diversity
}

\author{
ALlisOn MARIE LOCONTO' \\ INSTITUT NATIONAL DE LA RECHERCHE AGRONOMIQUE \\ LABORATOIRE INTERNATIONAL RECHERCHE INNOVATION ET SOCIETE \\ UNIVERSITE PARIS-EST MARNE-LA-VALLEE
}

\author{
DAVID DEMORTAIN ${ }^{2}$ \\ INSTITUT NATIONAL DE LA RECHERCHE AGRONOMIQUE \\ LABORATOIRE INTERNATIONAL RECHERCHE INNOVATION ET SOCIETE \\ UNIVERSITE PARIS-EST MARNE-LA-VALLEE
}

\begin{abstract}
Standards have become an important object of investigation in social science and STS scholars have called for a more systematic program of research to study standards or standardization (Busch 2011; Timmermans and Epstein 2010). In this considering concepts paper, we engage with their program for a sociology of standards and propose a new way to think about standards and standardization as "spaces of diversity" so as to push our thinking forward about how standards, standardization and innovation processes are linked. We consider standardization as the dynamic interaction in three spaces (standards in the making, standards in action, and standards in circulation) where diversity reemerges only to be tentatively reduced or limited through new rounds of standard setting. We illustrate how diversity is an integral part of standardization with the example of the Rainforest Alliance standard for tea production as it circulated from Costa Rica to Kenya, where it was made and put into action and then circulated again to other African, Asian, and Latin American countries. We end with a proposition for future research on standards to address these other spaces of standards as loci of standardization and innovation.
\end{abstract}

\section{Keywords}

standards; standardization; tea production; Rainforest Alliance; UTZ certified

Allison Marie Loconto, Email: allison-marie.loconto@inra.fr 2 David Demortain, Email: demortain@inra-ifris.org

Copyright (C) 2017 (Allison Marie Loconto and David Demortain). Licensed under the Creative Commons Attribution Non-commercial No Derivatives (by-nc-nd). Available at estsjournal.org. 


\section{Standardization and Diversity: Opposing Sides to the Standard Coin?}

Over the past twenty-five years, scholars have contributed to a growing body of literature that examines standards in their various forms (e.g., codes of conduct, guidelines, checklists, regulations, metrological samples) and in numerous fields (e.g., electricity, food safety, healthcare, industry, information technology) (Busch 2011; Bingen and Busch 2006). Perhaps the most generic finding stemming from this research is that a world in which standards proliferate is not necessarily a more homogeneous and standardized world (Timmermans and Epstein 2010). Standardization processes produce homogeneity, but also new diversities. Those new diversities are found not only when standards are built, discussed and settled, but also-according to Timmermans and Epstein-as a standard progresses out of a standards-setting arena, through implementation to meeting resistance and creating outcomes. In other words, the outcomes of standardization vary widely. ${ }^{3}$ These scholars call for further research in the area, particularly about "the collateral damage that standardization may cause for those who defy standardization, as well as trace the ironies of unintended consequences" (Timmermans and Epstein 2010, 84).

While we agree that there are indeed outcomes and consequences of standards that need to be explored, we want to propose that the above perspective on standardization is limited by the assumption that the outcome of standardization emerges through the local resistance, acceptance or translation of standards that are set in some distant, centralized place. Our view is that the typology found in Timmermans and Epstein (2010) still draws on a linear understanding of standardization that would altogether derive and depend on an initial act of standard setting. One problem with a focus on resistance and outcomes is that it represents local adoption, rejection or adaptation of standards as the end result of a process of standardization, leaving us with no conceptual tools to analyze why and how standards proliferate in the first place. Moreover, it fails to recognize the co-occurring processes that are typical of standardization: the continuing diversity that occurs in the context of proliferating enterprises of ordering, or what we might call concurrent regulation.

In this considering concepts piece, we draw upon a wide body of literature that has demonstrated how standardization is a way of producing order and regulating that does not proceed only from a centralized space of standards setting. For example, competition between standards (Granovetter and McGuire 1998; Farrell and Saloner 1988; Liebowitz and Margolis 1995; Büthe 2010; Garud, Jain, and Kumaraswamy 2002; Frankel and Højbjerg 2009), can lead to

${ }^{3}$ If standardization is a soft form of regulation (Brunsson \& Jacobsson 2000), it can also be viewed as a soft form of stratification, employed by myriad stakeholders to elevate some at the expense of others. Yet such stratification cannot be assumed simply on the basis of the presence of standards. Standardization is an active process that aspires to stability and order. Any order is a hard-won achievement that requires the submission of diverse actors. Standardization consists of building a society around a standard with an implied script that brings people and things together in a world already full of competing conventions and standards.

"Furthermore, it fails to reflect the particularity of "standards," since even the law has this property of being variable, diverse, and interpretable, as Weber's legal sociology has shown. 
the setting of more and newer standards, often by the same organizations (Sandholtz 2012) in cycles of opening up and closing down diversity (cf. Tushman, Anderson, and O'Reilly 1997; Abernathy and Clark 1985; Rosenkopf and Tushman 1994). Another group of scholars have highlighted actor and process diversity in new types of standards (e.g., process, performance), which devise operations at the local level rather than inscribe them in detail in the standard (Brunsson and Jacobsson 2000; Brunsson, Rasche, and Seidl 2012). We see movement towards greater autonomy for potential rule takers, intermediaries, users and certifiers, thus eliciting their consent and ensuring the wider applicability of the standard (Brunsson 2000; Brunsson and Jacobsson 2000; Botzem and Dobusch 2012; van den Ende et al. 2012; Abbott, Levi-Faur, and Snidal 2017; Cashore 2002; Botzem and Quack 2006; Djelic and Sahlin-Andersson 2006; Quack 2010; Boström 2006; Hülsse and Kerwer 2007; Hülsse 2008; Black 2008; Tamm Hallstrom and Boström 2010; Ransom et al. 2017).

The changes seen in standards and in the standardization processes they bring about are partly a result of a greater understanding of the non-standardized behavior that arises in the use of standards and of the discrepancies found in how standards are controlled by different authorities (Bingen and Busch 2006; Hatanaka, Bain, and Busch 2006; Bain, Ransom, and Worosz 2010). This is an analytical improvement to situations in which diversity was neither accounted for in the creation of a standard nor in the expectations regarding its implementation (Auld, Gulbrandsen, and McDermott 2008; Ponte 2012; Ouma 2010; Houghton and Jubb 2003; McDermott 2012). However, the co-existing tensions between "differentiated standardization" and "standardized differentiation" suggest that an even more nuanced analytical entry point is needed (Hatanaka, Bain and Busch 2006).

\section{Spaces of Diversity}

We contend that in processes of standardization, the active use of a standard is always partly a reinvention of rules and reallocation of responsibilities for implementing those rules. Given the fluidity or transitiveness of standard-setting authority and the diversity of objects that can be subject to standardization-including the various motives and instruments of standardization and the finite character of standards - engaging in applying a standard can often give rise to its reinvention and transformation. That is, rulemaking and rule use cannot easily be distinguished, and, indeed, perhaps the greatest puzzle of standardization is its never-ending dynamics.

Our provocation is, thus, that an approach to standardization that limits itself to the setting of the standard would be incomplete. It would not attend to the creativity of what is happening around standards, in practice, which generate further proliferation of standards. We argue that standards-like other technical objects-take on lives of their own (Simondon 1989 [1958]; Selznick 1949) and that they evolve (and thus are multiple) over time. Standardization can therefore be defined as a process of controlling and framing diversity, rather than one of only

${ }^{5}$ See MacKenzie's (2016[2008]) notion of rule finitism, that describes well what a standard is: a rule that does not exhaust the description of possible ways of applying it, and has no imposed structure of enforcement attached to it. 
reducing it. We suggest approaching standardization as the complex outcome of engagement with rules in three distinct, but related spaces: standards in the making, standards in action, and standards in circulation.

Standards in the making is where standards-making bodies, experts and other interested stakeholders assemble to construct standards as outcomes of negotiations and strategic action amongst these various actors (Bowker and Star 1999; Krislov 1997). This is the classically studied process of standardization as a site in which the negotiation around key values, qualities, knowledge, and semantics take place. Here, the process of creating a standard is the closing down of possible contestations in order to create a static, codified object--a standard. A standard passes through this space during different periods in its life: its inception, its revision, and, in some cases, its disappearance as it is institutionalized into law.

Standards in action meet users and enforcers in specific geographic spaces. Users make efforts to apply (or act in compliance with) a given standard in one locale (e.g., a country) so as to align with existing practices of production. In this space we see multiple enactments by users of the values that standards are meant to embody. Here, the standards themselves operate like immutable mobiles (Latour 1987) in that they are rigid in their boundaries so as to gain widescale applicability and legitimacy in markets and amongst users. Yet, since standardizing practices take shape in reality here, we see multiple enactments of different values as the common language of the standard is interpreted and appropriated differently (Loconto 2010). Despite the immutability of the standard, politics also thrive in this space as both the values and the actors co-evolve to fit each other (Busch 2011). This effort is put into place with the help of those involved in enforcing the standard (from official inspectors to consultants, accreditors, certifiers and auditors). Here, the standard can also be mobilized as a resource for different local projects (Loconto 2014, 2015b, 2015a). The actors engaging in this space necessarily negotiate the rigidity of standards; otherwise, it would be impossible to pass required audits (Gibbon, Lazaro, and Ponte 2010). More generally, the wording of standards can range from the very specific to the generic. Thus, the very semantics of a standard means that there is significant flexibility found in this space on the content, procedures, and control that are exercised as the standard is enacted in practice.

The resulting standardization process is not just restricted to those production practices that would enable a producer to conform to the standard; we see increasingly new activities emerge in standardizing or diversifying new rules for control (Loconto 2017), which also have impacts on what aspects of the standards are implemented or not. In fact, in actual settings in which standards must be followed, the added recourse to controlling and certification procedures, as a means to ensure standardization, paradoxically contributes to increasing diversity and multiplicity throughout standardization processes. The demonstrations of this unexpected diversity are twofold and complementary. On the one hand, although certifying bodies are often encouraged to become accredited in order to create uniformity in their competencies, most of the time they are in competition with one another for clients in a certification market (Fouilleux and Loconto 2016; Reinecke, Manning, and von Hagen 2012). That competition means that the ways in which standards are controlled can vary from one 
certification body to the next. On the other hand, certifiers may present very different organizational models as they have been set up in various circumstances and various local contexts (Galland 2017). This too produces diversity in standards systems.

Standards in circulation refers to the sense in which standards circulate in diverse geographic locales and sociocultural contexts. The outcome of acting with a standard in a given locale will often serve as a point of departure for further standardization, thus the state of affairs achieved with the diffusion of one standard is provisional. While closure around certain practices, competences, and ontologies will occur with the implementation of a standard in one setting, this situation is very likely to be reopened, the same standard being reconsidered in another locale, as it is combined with other standards, or revised to take a new form or incorporate newly observed emergent practices. These circulations give rise to new interpretations of the standard, or versions of it, by some of the same actors. This is particularly the case where for-profit standard intermediaries (large third-party certifiers) are involved. At international levels, there are often efforts to harmonize or calibrate standards applied in different economic areas or on related subjects, often resulting in the production of metastandards or principles for different aspects of control (Loconto and Fouilleux 2014; Loconto 2017).

The circulation of standards also has the effect of harmonization and standardization in the sense that it can bring the diversity of practice back into a process of revising a standard, which is the creation of standards in a bottom-up process of social learning, such as is fundamental to sociotechnical transitions (cf. Grin et al., 2010). Thus, the process of circulation can both redeliver diversity in standard practices and reduce diversity as practices converge to form a new or revised standard, only to be reopened again. In other words, the local "outcomes" or "consequences" of working with a defined standard are generally the start of a further process of (re)defining standards. It seems to us, then, that standardization has more to do with circulation than closure, insofar as some actors, including some that would count as "rule takers" or users, would often organize to theorize their relation to the standard, propose changes, and put new forms of standardization into circulation.

\section{Standardization Spaces in Sustainable Agriculture}

We explain our conceptualization of standardization as spaces of diversity with the example of the Rainforest Alliance tea standard. In this case, we find that our point of departure is already a space of circulation. The original Sustainable Agriculture Network standard that is managed by the Rainforest Alliance (RA) was created in Costa Rica in 1992 for sustainable farming in rainforest areas. The object of standardization was unsustainable forestry practices and the promotion of shade grown coffee in order to achieve the objective of rescuing a specific frog species from extinction. It wasn't until 2007 when a group of experts from Costa Rica, the Netherlands, France, and the US visited the Unilever tea plantation in Kenya to set a new standard for tea, that a new space of standards in the making was opened. Between 2007 and 2008, the small group of RA experts (marketing, agronomy, ecology) met regularly with the 
Unilever tea experts in Kericho, Kenya, and sustainable agriculture experts in Colworth, UK, to write the tea standard. During these discussions, Unilever held a monopoly on knowledge about conventional tea production and was using the revision of the RA standard as a means to differentiate its products in the market for "sustainable" products. The experts chose Kenya, because, unlike India, the conventional tea production system used no pesticides, few herbicides, had large tracks of indigenous forests within the plantation landholdings, and was the largest exporter of tea. The result was a quick standard setting process with no competition between actors, which resulted in a standard that was to be applied around the world, particularly in Unilever holdings, by 2015.

The Unilever plantations in Kenya became certified in 2008 (coinciding with the release of the standard) and passed with flying colors (over $80 \%$ compliance). However, putting the RA standards in action in Kenya, within the plantation setting, has produced new interpretations of the tea standard that Unilever helped to create. For example, biodiversity conservation and waste management criteria were areas where the existing practices were not in line with the RA standard. Unilever Tea Kenya owns 20 tea estates and eight factories on 6565 hectares of land in the Kericho and Bomet counties of southwest Kenya. When these estates began to put the RA standards into action, the result was that just two indicators of standards compliance became the defining characteristics of the meaning of sustainable agriculture for local actors: documenting indigenous species and recycling plastic bottles (recycling nutrients as proposed by the standard was not a salient requirement for standards compliance). In these cases, discrete opportunities arose for local actors to standardize their practices in some respects, but they also instantiated a clear divergence from the standardization of tea production as specified in the original RA standard. But the specificity of following the RA standard in these sites also provided the occasion for the redevelopment of the RA standard. For example, through the efforts to document indigenous tree, bird and frog species, which was required by the RA standard, the plantation managers became aware of the traditional bark removal practices by the local communities. This bark is used in traditional medicine and has been harvested for millennia. However, standards for bark removal were not included in the first RA standard, and so negotiations ensued about how to enforce a control mechanism over sustainable bark removal. This activity then contributed to redefining the practice of "local community engagement," which is another critical criterion of the standard.

The RA standard was put into circulation first in Unilever plantations in Tanzania and India in 2008, and then more broadly in plantations and smallholder farms across East Africa, South Asia, and Latin America. This circulation has influenced the dynamics of standardization more broadly. Specifically, once the RA tea standard was released and began to be implemented, it quickly entered into competition for clients with the UTZ certified standard for tea, which was released shortly after the RA standard. The UTZ suite of standards are focused on good agricultural practices and are known for their sophisticated traceability systems. Traceability is

"UTZ certified was created in 2002 with the original name of "UTZ kapeh" meaning "good coffee" in Quiché, a Mayan language. 
very important for complying with public food safety and import standards, and many producers were required to adopt this standard as well. In 2011, the first effort at calibrating the two standards occurred, with a joint statement by RA, UTZ, and Fairtrade International proposing to develop "tools and materials to enable adherence to multiple Standards." Finally, in 2017, Rainforest Alliance and UTZ announced that they would begin a consolidation process whereby they would combine their standards to create a new standard and a new organization that can ensure that "more products are responsibly sourced."s

\section{Conclusion}

We suggest that the above described enterprises of ordering constitute discrete spaces of standardization (making, acting, circulating), but should be understood as coexisting and interconnected networks in which a given set of actors try to create order around a given rule and allocation of responsibilities. We believe that these are natural dynamics of standards and not the result of concerted resistance. Difference is not necessarily an instance of resistance to standards, but rather a fundamental component of compliance with them. In other words, a given standard can have several lives simultaneously in these different spaces, diffracting into several new standardizing enterprises that unfold through a process of circulation that simultaneously both fosters and suppresses diversity.

With this reconceptualization of standardization, we propose pushing the sociology of standards beyond the recognition of the opening up and closing down of diversity in the "standards in the making" space. We suggest that there is value in considering standardization as the dynamic interaction in spaces where diversity reemerges only to be tentatively reduced or limited through new rounds of standard setting. It is this dynamic vision of extension through and between different spaces that suggests a methodological point. That is, scholars of standardization and diversity should pay specific attention to the interactions between the spaces we have identified. Adaptation and revision of standards are activities that are formally recognized during the standards setting and the conformity assessment process. Thus, when there is communication between actors around these processes, diversity can also arise. This suggests that the actors involved in the circulation of standards are as important and as politically significant as those found also in the other spaces that have thus far received the majority of analytic attention. Therefore, we propose that future research on standards should begin to address these other spaces of standards as we may learn more about the different paths in which multiplicity and plurality can be expressed and oppressed.

This conceptualization helps us to understand why and how diversity arises in tandem with standardization processes, even though harmonization, homogeneity or interoperability are supposed to be their only purpose. It also stresses the need for further research on the

https: / / www.isealalliance.org/online-community / news / historic-joint-statement-fairtrade-sanrainforestalliance-utz-certified, accessed 04/08/2017.

${ }^{8}$ http:/ / www.rainforest-alliance.org/article/rainforest-alliance-utz-merger, accessed 04/08/2017. 
understudied spaces of standards in action and circulation, and on the activities, that connect the three spaces together and encourage the movement from one space to the next. The spaces of action concept could help scholars to better follow not only the standards, but also the diverse actors in their dynamic interactions that constitute standardization processes. This framework can help to broaden the scope of standards research to better capture the ways in which diversity might be better controlled or encouraged through innovation. Moreover, it can better capture the transnational and scalar nature of dynamic standardization processes that are not easily classified as occurring at the site in which standards are created.

\section{References}

Abbott, Kenneth, David Levi-Faur, and Duncan Snidal. 2017. "Theorizing Regulatory Intermediaries: The RIT Model." The Annals of the American Academy of Political and Social Science.

Abernathy, William J., and Kim B. Clark. 1985. "Innovation: Mapping the winds of creative destruction." Research Policy 14 (1):3-22. doi: 10.1016/ 0048-7333(85)90021-6.

Auld, Graeme, Lars H. Gulbrandsen, and Constance L. McDermott. 2008. "Certification Schemes and the Impacts on Forests and Forestry." Annual Review of Environment and Resources 33 (1):187-211. doi: doi:10.1146/annurev.environ.33.013007.103754.

Bain, Carmen, Elizabeth Ransom, and Michelle Worosz. 2010. "Constructing Credibility: Using Technoscience to Legitimate Strategies in Agrifood Governance." Journal of Rural Social Science 25 (3):160-192.

Bingen, R. James, and Lawrence Busch. 2006. Agricultural standards: the shape of the global food and fiber system, The international library of environmental, agricultural and food ethics. Dordrecht: Springer.

Black, Julia. 2008. "Constructing and contesting legitimacy and accountability in polycentric regulatory regimes." Regulation \& Governance 2 (2):137-164. doi: 10.1111/j.17485991.2008.00034.x.

Boström, Magnus. 2006. "Regulatory Credibility and Authority through Inclusiveness: Standardization Organizations in Cases of Eco-Labelling." Organization 13 (3):345-367. doi: $10.1177 / 1350508406063483$.

Botzem, Sebastian, and Leonhard Dobusch. 2012. "Standardization Cycles: A Process Perspective on the Formation and Diffusion of Transnational Standards." Organization Studies 33 (56):737-762. doi: $10.1177 / 0170840612443626$.

Botzem, Sebastian, and Sigrid Quack. 2006. "Contested rules and shifting boundaries: International standard setting in accounting " In Transnational Governance: Institutional Dynamics of Regulation, edited by M Djelic and K Sahlin-Andersson. Cambridge, MA: Cambridge University Press.

Bowker, Geoffrey C., and Susan Leigh Star. 1999. Sorting things out: classification and its consequences, Inside technology. Cambridge, MA: MIT Press. 
Brunsson, Nils. 2000. "Organizations, Markets, and Standardization." In A World of Standards, edited by Nils Brunsson and Bengt Jacobsson, 21-39. Oxford: Oxford University Press.

Brunsson, Nils, and Bengt Jacobsson, eds. 2000. A World of Standards. Oxford, UK: Oxford University Press.

Brunsson, Nils, Andreas Rasche, and David Seidl. 2012. "The Dynamics of Standardization: Three Perspectives on Standards in Organization Studies." Organization Studies 33 (5-6):613-632. doi: $10.1177 / 0170840612450120$.

Busch, Lawrence. 2011. Standards: Recipes for Reality. Cambridge, MA: MIT Press.

Büthe, Tim. 2010. "Engineering Uncontestedness? The Origins and Institutional Development of the International Electrotechnical Commission (IEC)." Business \& Politics 12 (3):1-62. doi: 10.2202/1469-3569.1338.

Cashore, Benjamin. 2002. "Legitimacy and the Privatization of Environmental Governance: How Non-State Market-Driven (NSMD) Governance Systems Gain Rule-Making Authority." Governance: An International Journal of Policy, Administration, and Institutions 15 (4):503-529.

Djelic, M.L., and K. Sahlin-Andersson. 2006. Transnational Governance: Institutional Dynamics of Regulation: Cambridge University Press.

Farrell, Joseph, and Garth Saloner. 1988. "Coordination through Committees and Markets." RAND Journal of Economics 19 (2):235-252.

Fouilleux, Eve, and Allison Loconto. 2016. "Voluntary standards, certification, and accreditation in the global organic agriculture field: a tripartite model of techno-politics." Agriculture and Human Values:1-14. doi: 10.1007/s10460-016-9686-3.

Frankel, Christian, and Erik Højbjerg. 2009. "The Political Standardizer." Business \& Society 51 (4):602-625. doi: $10.1177 / 0007650309332311$.

Galland, Jean-Pierre. 2017. "Big Third-Party Certifiers and the Construction of Transnational Regulation." The Annals of the American Academy of Political and Social Science.

Garud, Raghu, Sanjay Jain, and Arun Kumaraswamy. 2002. "Institutional Entrepreneurship in the Sponsorship of Common Technological Standards: The Case of Sun Microsystems and JAVA." Academy of Management Journal 45 (1):196-214. doi: 10.2307/3069292.

Gibbon, Peter, Evelyne Lazaro, and Stefano Ponte. 2010. Global agro-food trade and standards : challenges for Africa, International political economy series. Houndmills, Basinstoke, Hampshire ; New York, NY: Palgrave Macmillan.

Granovetter, Mark, and Patrick McGuire. 1998. "The making of an industry: electricity in the United States." In The Laws of the Markets, edited by Michael Callon, 147-173. Oxford: Blackwell.

Hatanaka, Maki, Carmen Bain, and Lawrence Busch. 2006. "Differentiated Standardization, Standardized Differentiation: The Complexity of the Global Agrifood System." In Between the Local and the Global: Confronting Complexity in the Contemporary Agri-food Sector, edited by Terry Marsden and Jonathan Murdoch, 39-68. Oxford, UK: Elsevier.

Houghton, Keith A., and Christine A. Jubb. 2003. "The Market for Financial Report Audits: Regulation of and Competition for Auditor Independence." Law \& Policy 25 (3):299-321. doi: doi:10.1111/j.1467-9930.2003.00152.x. 
Hülsse, Rainer. 2008. "Even clubs can't do without legitimacy: Why the anti-money laundering blacklist was suspended." Regulation \& Governance 2 (4):459-479. doi: 10.1111/j.17485991.2008.00046.x.

Hülsse, Rainer, and Dieter Kerwer. 2007. "Global Standards in Action: Insights from Anti-Money Laundering Regulation." Organization 14 (5):625-642. doi: doi:10.1177/ 1350508407080311.

Krislov, Samuel. 1997. How Nations Chose Product Standards and Standards Change Nations. Pittsburgh: University of Pittsburgh Press.

Latour, Bruno. 1987. Science in Action: How to Follow Scientists and Engineers through Society. Milton Keynes, England: Open University Press.

Lefebvre, Henri. 1974. La production de l'espace. Paris: Éditions Anthropos.

Liebowitz, Stan J., and Stephen E. Margolis. 1995. "Path Dependence, Lock-In, and History." Journal of Law, Economics and Organization 11 (1):205-226. doi: 10.2139/ssrn.1706450.

Loconto, Allison. 2010. "Sustainably Performed: Reconciling Global Value Chain Governance and Performativity." Journal of Rural Social Science 25 (3):193-225.

Loconto, Allison. 2014. "Sustaining an Enterprise, Enacting SustainaibliTea." Science, Technology E Human Values 39 (6):819-843. doi: 10.1177/0162243914531989.

Loconto, Allison. 2015a. "Assembling governance: the role of standards in the Tanzanian tea industry." Journal of Cleaner Production 107:64-73. doi: http:/ / dx.doi.org/10.1016/j.jclepro.2014.05.090.

Loconto, Allison. 2015b. "Can Certified-Tea Value Chains Deliver Gender Equality in Tanzania?" Feminist Economics 21 (3):191-215. doi: 10.1080/13545701.2014.1001765.

Loconto, Allison. 2017. "Models of Assurance: Diversity and Standardization of Modes of Intermediation." The Annals of the American Academy of Political and Social Science 670 (1):112-132.

Loconto, Allison, and Eve Fouilleux. 2014. "Politics of Private Regulation: ISEAL and the shaping of transnational sustainability governance." Regulation $\mathcal{E}$ Governance 8 (2):166-185. doi: 10.1111 / rego.12028.

MacKenzie, Donald. 2016 [2008]. "Producing Accounts: Finitism, Technology and Rule Following." In Knowledge as Social Order: Rethinking the Sociology of Barry Barnes, edited by M. Mazzotti. New York: Taylor \& Francis.

McDermott, Constance L. 2012. "Trust, legitimacy and power in forest certification: A case study of the FSC in British Columbia." Geoforum 43 (3):634-644. doi: 10.1016/j.geoforum.2011.11.002.

Ouma, Stefan. 2010. "Global Standards, Local Realities: Private Agrifood Governance and the Restructuring of the Kenyan Horticulture Industry." Economic Geography 86 (2):197-222. doi: 10.1111/j.1944-8287.2009.01065.x.

Ponte, Stefano. 2012. "The Marine Stewardship Council (MSC) and the Making of a Market for 'Sustainable Fish'." Journal of Agrarian Change 12 (2-3):300-315. doi: 10.1111/j.14710366.2011.00345.x. 
Quack, Sigrid. 2010. "'" Global" Markets in Theory and History: Towards a Comparative Analysis." In Wirtschaftssoziologie. Kölner Zeitschrift für Soziologie und Sozialpsychologie, Sonderheft 49, 125-142. VS Verlag für Sozialwissenschaften.

Ransom, Elizabeth, Maki Hatanaka, Jason Konefal, and Allison Loconto. 2017. "Science and Standards." In The Routledge Handbook of the Political Economy of Science, edited by David Tyfield, R Lave, S Randalls and C Thorpe, 328-340. New York: Routledge.

Reinecke, Juliane, Stephan Manning, and Oliver von Hagen. 2012. "The Emergence of a Standards Market: Multiplicity of Sustainability Standards in the Global Coffee Industry." Organization Studies 33 (5-6):791-814. doi: 10.1177 / 0170840612443629.

Rosenkopf, L, and M Tushman. 1994. "The Co-evolution of Technology and Organization." In Evolutionary Dynamics of Organizations, edited by J Baum and J Singh. Oxford: Oxford University Press.

Sandholtz, Kurt W. 2012. "Making Standards Stick: A Theory of Coupled vs. Decoupled Compliance." Organization Studies 33 (5-6):655-679. doi: 10.1177/0170840612443623.

Selznick, Philip. 1949. TVA and the grass roots; a study in the sociology of formal organization. Berkeley,: Univ. of California Press.

Simondon, Gilbert. 1989 [1958]. Du mode d'existence des objets techniques. Ed. augm. / ed, L'invention philosophique. Paris: Aubier.

Tamm Hallström, Kristina. 2004. Organizing international standardization: ISO and the IASC in quest of authority. Cheltenham, UK ; Northampton, MA: Edward Elgar.

Tamm Hallstrom, Kristina, and Magnus Boström. 2010. Transnational multi-stakeholder standardization : organizing fragile non-state authority. Northampton, MA: Edward Elgar Pub. Inc.

Timmermans, Stefan, and Steven Epstein. 2010. "A World of Standards but not a Standard World: Toward a Sociology of Standards and Standardization." Annual Review of Sociology 36 (1):69-89. doi: doi:10.1146/annurev.soc.012809.102629.

Tushman, Michael L., Philip C Anderson, and Charles O'Reilly. 1997. "Technological cycles, innovation streams, and ambidextrous organizations: organizational renewal through innovation streams and strategic change." In Managing strategic innovation and change: $A$ collection of readings, edited by Michael Tushman and Philip Anderson. New York: Oxford University Press.

van den Ende, Jan, Geerten van de Kaa, Simon den Uijl, and Henk J. de Vries. 2012. "The Paradox of Standard Flexibility: The Effects of Co-evolution between Standard and Interorganizational Network." Organization Studies 33 (5-6):705-736. doi: $10.1177 / 0170840612443625$. 